\title{
Pills are not the answer to unhealthy lifestyles
}

\author{
Fiona Godlee editor in chief
}

The BMJ

More than half of adults aged over 45 will be labelled as hypertensive if new US guidelines are adopted, concludes a study in The BMJ this week (doi:10.1136/bmj.k2357). This equates to 70 million people in the US and 267 million people in China being eligible for antihypertensive drugs, a marked increase on already high rates of drug treatment for high blood pressure. Furthermore, the study calculates that 7.5 million people in the US and 55 million in China would be advised to start drug treatment, while 14 million in the US and 30 million in China would be advised to receive more intensive treatment. The evidence from trials indicates some benefit from drugs in terms of reduced risk of stroke and heart disease, but is mass medication really what we want?

Hypertension is just one of the many heads of the lifestyle disease hydra. Another is type 2 diabetes. Once thought to be irreversible and progressive, it is now known to be potentially reversible through weight loss. This is the cautious conclusion of the review by Nita Forouhi and colleagues (doi:10.1136/bmj. $\mathrm{k} 2234$ ), part of our series on the science and politics of nutrition (bmj.com/food-for-thought). Whether by calorie or carbohydrate restriction, weight loss has been shown to improve glycaemic control, blood pressure, and lipid profile and is the key to treatment and prevention of type 2 diabetes, they say.

What about non-alcoholic fatty liver disease (NAFLD), now estimated to affect more than a quarter of adults and up to $90 \%$ of people with obesity or type 2 diabetes? This too is largely a disease of lifestyle, closely linked to overweight and obesity, as well as type 2 diabetes and heart disease. You can read about how to diagnose and monitor patients with NAFLD in the review by Christopher Byrne and colleagues (doi:10.1136/bmj.k2734). As for treatment, again it's down to weight loss through diet and exercise. There are currently no FDA approved drug treatments. There are, however, about 100 drugs currently going through phase II and III clinical trials, and the NAFLD market is estimated to be worth $\$ 1$.6bn ( $£ 1.2 \mathrm{bn}$; $€ 1.4 \mathrm{bn}$ ) by 2020 . $^{1}$

This is an appalling prospect. All health systems are under pressure, and it's right that we stop doing things that don't work, as Ann Robinson finds (doi:10.1136/bmj.k3028). But pills can't be the answer to diseases caused by unhealthy living. As well as unsustainable cost for often marginal benefit, they always cause harm. Rather than medicating almost the entire adult population, let's invest our precious resources in societal and lifestyle change, public health, and prevention.

1 Nonalcoholic steatohepatitis drug pipeline overview. Pharmacy Times. Sep 2016. https:/ /www.pharmacytimes.com/contributor/ryan-chandanais-ms-cpht/2016/09/nonalcoholicsteatohepatitis-drug-pipeline-overview.

Published by the BMJ Publishing Group Limited. For permission to use (where not already granted under a licence) please go to http://group.bmj.com/group/rights-licensing/ permissions 